\begin{tabular}{ccc}
\hline & International Journal of Engineering \& Technology, $7(2.32)(2018) 355-358$ \\
SPC & International Journal of Engineering \& Technology \\
Website: www.sciencepubco.com/index.php/IJET & Research paper \\
\hline
\end{tabular}

\title{
Quick Identification of Specific Activity by Processing of Large-Size Videos Using Advanced Spotter
}

\author{
Dr.S.Hrushikesava Raju ${ }^{1}$, Dr.M.Nagabhushana Rao ${ }^{2}$, Dr.N.Sudheer ${ }^{3}$, Dr.P.Kavitharani ${ }^{4}$ \\ ${ }^{1,4}$ Professor, Dept. of CSE, Siddharth Institute of Engineering \& Technology, Puttur, Andhra Pradesh \\ ${ }^{2}$ Professor, Dept. of CSE, KL E F, Vijayawada, Andhra Pradesh \\ ${ }^{3}$ Associate Professor, Dept. of CSE, Siddharth Institute of Engineering \& Technology, Puttur, Andhra Pradesh \\ *Corresponding author E-mail: hkesavaraju@gmail.com
}

\begin{abstract}
Now-a-days, the most organizations are using cameras at all places in order to monitor the activities going in their daily works $24 / 7$ type. The purpose of recording all activities is to provide security and safeness to the property of their organization, as well as to find out the thefts happened or to identify any odd behavior of person about the complained situation. In this context, It takes more time to watch the long length video in predicting the right entity. There were other methods which require witness of some persons and time of the day. It is a manual approach to check the scene in the video recorded. It is unreliable. The alternative approach proposed is usage of advanced spotter in which cameras with sensors were attached in all places. The benefits of this proposed study is automatic fixing of spot in the recording of the videos when the objects behavior is predicted beyond the normal level. Hence, this automatic approach helps to the organizations where less time taken to find out the odd scenes which are tracked by the advanced spotter.
\end{abstract}

Keywords:Organizations, spotter, recorded videos, time, automatic.

\section{Introduction}

In the olden days, there are many manual approaches to enquiry about some event happened which might involves robbery, theft, murder, identifying whether a person is attended the office or not in relevance to the case given, and etc. First approach is purely manual method in which the enquiry starts by interacting with many objects like persons to know about the truth of the happened event. This method is much waiting take taking process in solving the problem. The duration may be 1 day to few days to even a month. Second is semi manual method in which both equipment and persons interaction are involved. This method involves watching of equipment like web cameras in identifying the actuals and requires interactions with the persons. It is some-how better performance than purely manual method. It takes less time to predict the solution for the problem raised. To overcome delay in time to provide a solution for the event occurred, a novel method is required which is fully dependent on the equipment using spotter as a mark in the recording of a video and less dependent on interaction with required persons. This method has more accuracy in giving the solution for a given problem. There are many benefits of using advanced spotter software in the sensor-ed inbuilt cameras.

Here is a list of methods used in solving a problem ad their disadvantages and advantages are mentioned along with them.

Table 1. Comparison of methods used for solution

\begin{tabular}{|l|l|l|}
\hline Method Name & Disadvantage & Advantage \\
\hline Manual method & $\begin{array}{l}\text { Requires persons } \\
\text { response, time for the } \\
\text { solution is not guaran- } \\
\text { teed, forgery may be }\end{array}$ & $\begin{array}{l}\text { Solution might be depend- } \\
\text { ent on persons related to the } \\
\text { event occurred }\end{array}$ \\
\hline
\end{tabular}

\begin{tabular}{|l|l|l|}
\hline & allowed & \\
\hline $\begin{array}{l}\text { Semi Manual } \\
\text { method }\end{array}$ & $\begin{array}{l}\text { Requires to interacts } \\
\text { with equipment like } \\
\text { camera for watching } \\
\text { the video. }\end{array}$ & $\begin{array}{l}\text { 1) It better compared to } \\
\text { manual } \\
\text { 2) Solution guaranteed }\end{array}$ \\
\hline $\begin{array}{l}\text { Automatic } \\
\text { Method }\end{array}$ & $\begin{array}{l}\text { Dependent on the } \\
\text { software in the equip- } \\
\text { ment }\end{array}$ & $\begin{array}{l}\text { 1) Most better than earlier } \\
\text { methods } \\
\text { 2) Solution guaranteed }\end{array}$ \\
\hline
\end{tabular}

Among listed methods, automated method gives the result in less time and is not dependent on external people. Only operator is enough to give judgment about the specific activity happened.

\section{Proposed Methodology}

Here, the methodology taken is cameras with built in sensors using advanced spotter technology at the client side in order to get solution after the enquiry.

Here, the architecture and working functionality of this proposed model is brought out. Also, the advanced spotter software technology is developed using specific pseudo code.

The following specifies the pseudo code of proposed model:

Pseudo_Procedure Advanced_Spotter(Input Rvideo, Input SensorData):

Input: Rvideo, sensors

Output: video_with_spotters

1. First load sample clips in identifying and usage of tools or abnormal behaviors in the video recorded as an initial step. 
2. In recording the scenes itself, sensors will come into function based on tools used or abnormal behaviors.

3. Sensors will come into function based on activity. If such clips or abnormal behavior is found, spot is added using color markers. Yellow is used for usage of tools like knife, axe, chains and wild spare parts of a vehicle, green is used for usage of gun, pistols, and advanced mission guns, white is used for abnormal behavior like trying to escape from people, attacking on people, stolen kind of things, and etc., cyan for representing odd actions like moving of hands, and speed of talking with abuse words and etc. Like this, this customization will help to keep the colors in the recorded video.

4. Using these colored marks, the user can easily find the situations. The software developed will result output is video with spotters.

The advantage of advanced spotter facility in the organizations recorded videos is less time it took to identify the specific activity through colored marker rather than random point location and check. In future, every routine is becoming the automatic. This facility may become excellent rewarding in upcoming generations in identifying the odd scenes.

The following is the existing method what we are using :

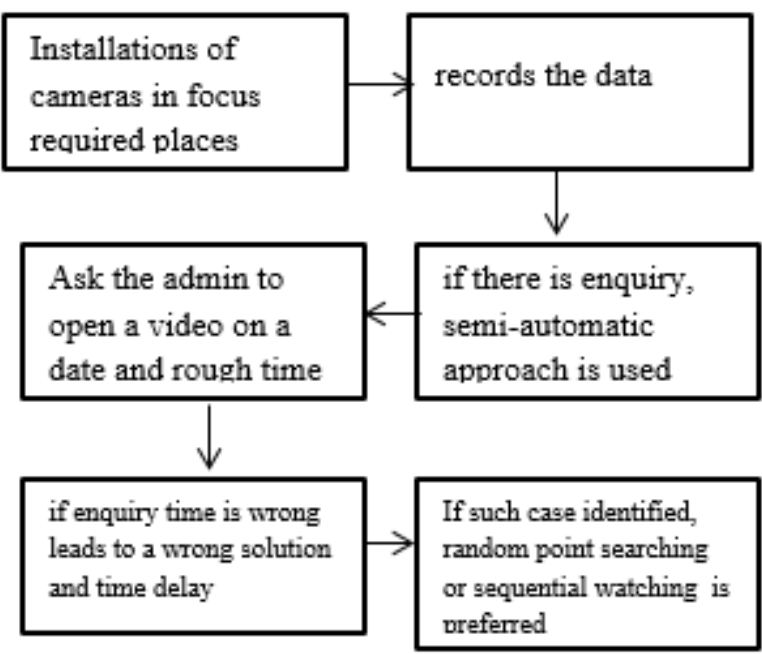

Fig.1. Working of Existing semi-automatic methodology

The above existing method requires some part dependent on machine and some part dependent on true people. This method involves identification of specific activity in the recorded video based on the input given by the people involved in the scene. If people involved gives wrong input, the time to give judgment should be delayed. To get the judgment in less time without any need of people for external help, an automated method using advanced spotter technology using sensors attached to the cameras that were installed.

The proposed method works on using sensors attached to each and every camera. The sensors will have to sense specific activities and sense any activity which is not fallen in the predefined activities list and make it as special mark compared to predefined markers in the recorded video. The activity fall under special will take different color "bright purple".

If any combination of activities is identified, their colors will be marked on the marker placed in the recorded video. If two activities combination are used in the scene, their equal sized colors are represented in the marker position in the video recorded. This automatic spotter will be user friendly and accurate in predicting the scenes using sensors in-built in them.
The following specifies the architecture of working of advanced spotter in processing of organizations large size videos of a day. The following is the existing method what we are using :

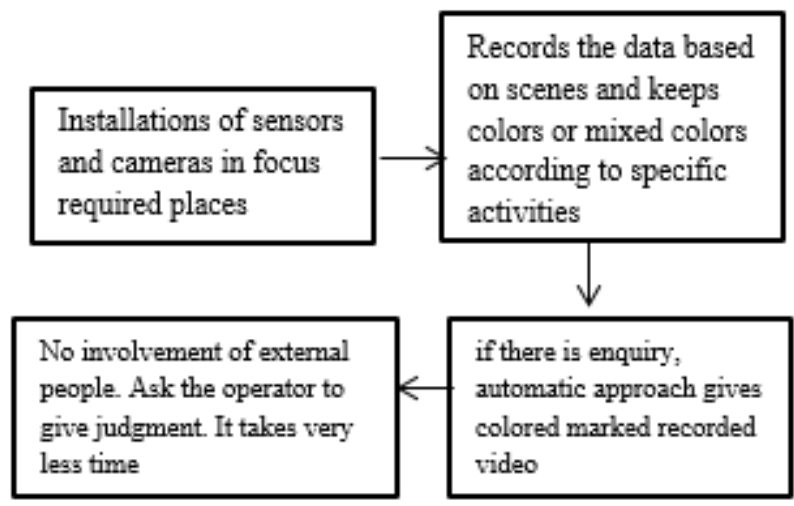

Fig.2. Working of automatic methodology using advanced spotter technology

The above method will be useful a lot in coming generations and is automatic.

When compared automatic method with semi-automated method, main factor influencing is time consumption in giving judgment, another factor is results provide accurate judgment whereas results may change because of un-trusty people involved in the scene in case of semi-automatic approach, and last but not least automatic approach is more customized. The automated approach includes time frames also in the recorded video. The time frame involves starting time of the activity and end time of that activity. This facility is useful a lot to the end user in seeing the specific activities using the time frames.

For the organizations, the Bosses or CEOs of that organization need not reside in the office, but they will monitor issues going to be raised during the working hours. This automated approach will enhanced by installing the appropriate sensors in the cameras to the level in which customized activities scenes will be posted so that clips involving customized actions will be posted to the management of the organization in order to assess the performance of the employee or staff working in that organization.

The customized advanced spotter working is depicted as follows:

\begin{tabular}{|c|c|}
\hline $\begin{array}{l}\text { Installations of } \\
\text { customized sensors } \\
\text { and cameras in focus } \\
\text { required places }\end{array}$ & $\begin{array}{l}\text { Records the data based } \\
\text { on scenes and keeps } \\
\text { colors or mixed colors } \\
\text { according to specific } \\
\text { activities }\end{array}$ \\
\hline \multirow[b]{2}{*}{$\begin{array}{l}\text { No involvement of external } \\
\text { people. The built-in spotter } \\
\text { software sends the clips to } \\
\text { the management so that } \\
\text { management aware of } \\
\text { working environment }\end{array}$} & $\downarrow$ \\
\hline & $\begin{array}{l}\text { if there is enquiry, } \\
\text { automatic approach gives } \\
\text { colored marked recorded } \\
\text { video }\end{array}$ \\
\hline
\end{tabular}

Fig.3. Working of automatic methodology using advanced spotter technology

The above customized spotter methodology, will be shaped and designed according to the demands of concerned management.

The detailed screens obtained using these two approaches are different and are listed in the results chapter.

\section{Results}


The existing method semi-automatic approach won't use any markers in order to indicate specific activities like robbery or stolen, harassing using abuse words, murdering someone, attacking etc.. For markening about specific activities in the recorded video, manual approach requires time to place markers. It is very much time taking process in predicting the specific event. This approach is not very much recommended and is less feasible in the considered application such as identification of specific events in processing of large size videos of an organization.

The following snapshot specifies the normal working procedure of semi-automated approach.

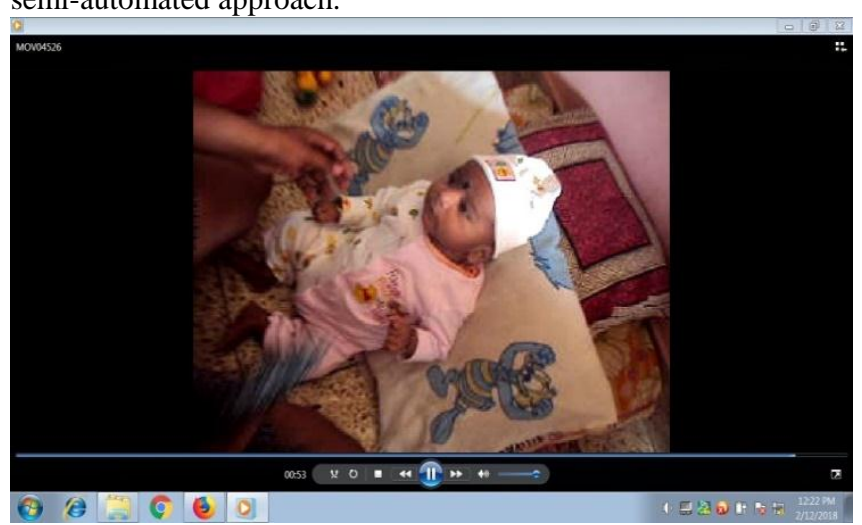

Fig.4. Example for semi- automatic methodology which won't have markers for indicating specific events

In order to overcome these issues, and to achieve the result in less time, advanced spotter software installed in sensor based cameras is preferred.

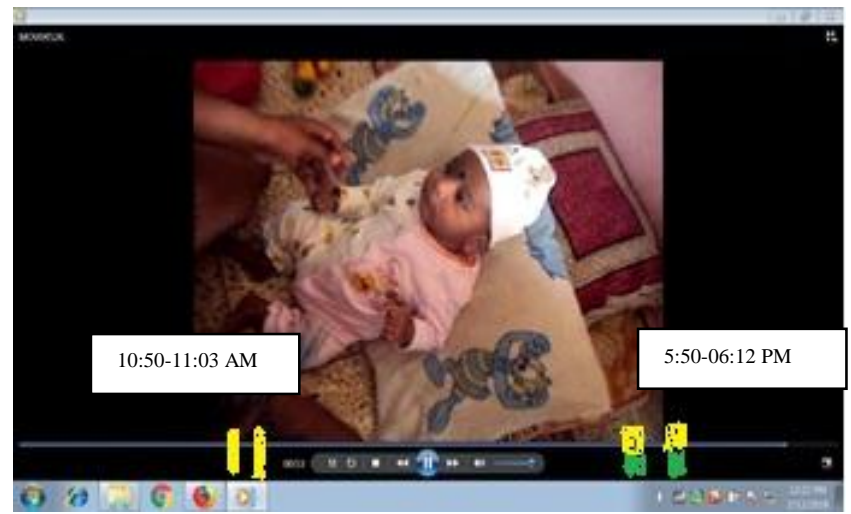

Fig.5. Example for automatic methodology which have colored markers for indicating specific events

In the above result obtained, there were colored markers placed at two points in the video. One is yellow colored marker indicates usage of tools like knife, axe, chains and wild spare parts of a vehicle, and second specifies combination of yellow and green in which some part involves usage of knifes, and other tools and other part consists of usage of gun, pistols, and advanced mission guns, etc.. This automatic method also specifies the duration that describes starting time slot and ending time slot in colored markers only. In first activity, time for starting of the activity at 10:50AM and end time of that activity is 11:03 AM , and the duration predicted is 10:03 minutes. The second activity also specifies the time duration 20:02 minutes that event is present in the recorded video from 5:50 PM to 6:12PM. The advantage of this advanced spotter software is judgment given in very less time using customized sensors facility built in cameras.

This automatic approach also be customized using organizations management requirements but respective sensors can be used in order to identify their customized videos.
The following represents the graph that shows the performance of semi-automatic and fully automatic advanced spotter technologies:

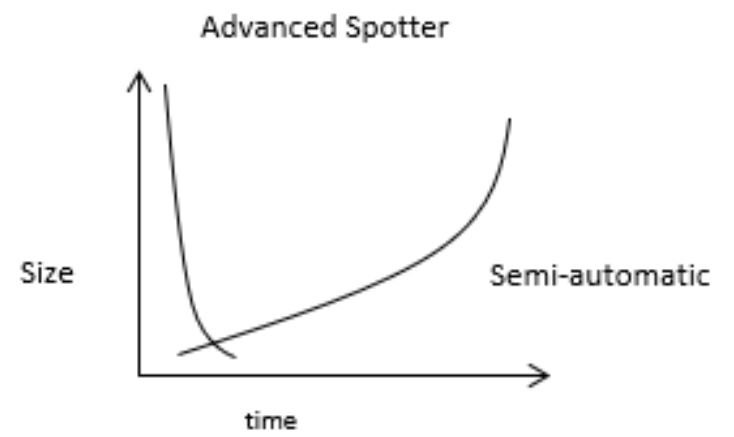

Fig.6. Performance of advanced spotter automatic and semi-automatic approaches w.r.to time and size

In terms of big size, semi-automatic method takes more time whereas automatic advanced spotter takes less time. In terms of less size, both the approaches but importantly proposed automatic advanced spotter will consume less time.

\section{Conclusion}

In future, the technology proposed might occupy every where in providing solution or a witness to all organizations based on their demand. The power of this technology is development of customized sensors in respective to particular organization requirements. The managements of the organizations will monitor their organizations inside activities easily without their present every day. The goal of this model is achieved such as identification of specific events in less time and is not dependent on involved people witness in giving the judgment. The quick judgment is guaranteed in this processing of large size videos using automatic advanced spotter technology through customized sensors.

\section{References}

[1] William Deutsch, Using Security Cameras While Respecting Privacy Tips for Implementing a Reasonable Surveillance Policy, https://www.thebalance.com/using-security-cameras-whilerespecting-privacy-394615, February 21, 2017.

[2] Record Video Presentations From Different Viewpoints With Multiple Cameras And Panopto, https://www. panopto.com/blog/engage-multi-cam-2/, July 21,2017.

[3] Use of cameras and audio/video recording devices at UNFCCC sessions, http://unfecc.int/press/items/5022.php.

[4] YOUR RIGHTSSurveillance at Work, https://www. workplacefairness.org/workplace-surveillance

[5] Pam Loch, Surveillance at work: the legal issues of using CCTV, https://www.personneltoday.com/hr/surveillance-the-legal-issuesof-cctv-use-at-work/, January 24, 2017.

[6] Surveillance Station, flexible and efficient, https://www. synology.com/en-global/solution/surveillance_large, copyright 2018 synology Inc. All rights reserved.

[7] Surveillance: Cameras in the Workplace, https://www.shrm org/resourcesandtools/tools-and-samples/policies/pages/ cms_015088.aspx, July 18, 2016.

[8] Ethan Bernstein, How being filmed changes in employee behavior, https://hbr.org/2014/09/how-being-filmed-changes-employeebehavior, September 12, 2014.

[9] Record Keeping for Non-Profit Organizations, http://www.omafra.gov.on.ca/english/rural/facts/08-059.htm, ISSN 1198-712X, December 2008.

[10] Privacy and CCTV - A Guide to Privacy Act for Businesses, agencies, and organizations, copyright 2018 synology Inc. All rights reserved. 
[11] Surveillance in the workplace, http://www. citizensinformation.ie/en/employment/employment_rights_and_conditions/m onitor-

ing_and_surveillance_at_work/surveillance_of_electronic_com munications_in_the_workplace.html, 4 April 2013

[12] Allea Grummert, Nonprofits: Video Equipment You Need to Get Started on a Budget, http://www. nonprofitfilmschool.com/blog/nonprofits-video-equipment-budget

[13] Using CCTV to monitor the workplace, https://www.icaew. com/archive/library/subject-gateways/business-management /smes/small-business-update/2015-01/using-cctv-to-monitor-theworkplace, 01 January 2015

[14] sanford-brown blogs-workplace monitoring: is it ethical and legal, http://www. sanfordbrown.edu/student-life/blog/ january2014/workplace-monitoring-is-it-ethical-and-legal, 20january, 2014

[15] advantages and disadvantages of using security cameras, https://www. alsecuritycameras.com/blog/advantagesdisadvantages-using-security-cameras/, 14 november, 2014 